Journal of Architectural Research and Development

Research Article

\title{
BIM Technology Application in Civil Engineering
}

Fei Sun

Zibo Vocational Institute, Zibo 255314, Shandong Province, China

Abstract: With the development of the times and science and technology, China has entered the era of digital information. Under the background of information technology, the civil engineering industry must develop standards and industry norms that are in line with the times and the development of technology so that the civil engineering industry can develop continuously, steadily and with high quality in the era of digital information technology. BIM technology, as a digital technology in the field of civil engineering, realizes the online, digital and intelligent of all elements, processes and participants in the whole life cycle of the project. This paper starts with the specific application of BIM technology to provide guidance for the smooth implementation of civil engineering projects.

Keywords: Bim technology; Civil engineering; Application

Publication date: September, 2020

Publication online: 30 September, 2020

* Corresponding a uthor: F e i S u n, zixuehu84055862@163.com

\section{Introduction}

With the development of the times, various construction projects keep appearing. Currently, there are more and more types of construction projects in China, and the forms of construction projects are becoming more and more complex. The construction project has become a building system that integrates several technical fields. In order to adapt to the background of the information age, it is necessary to accurately and efficiently transmit all aspects of construction project information. However, traditional models of construction engineering no longer meet the needs of the times and have been abandoned by the times. Therefore, it is necessary to actively seek an alternative construction model that is suitable for the background of the information age.

\section{Overview of BIM technology}

\subsection{Concept of BIM technology}

BIM (i.e. Building Information Modeling) builds a virtual building model according to the specific situation of the project under construction, inputs relevant project information parameters into the model, and builds a three-dimensional digital building model based on information technology. The model is synchronized to the virtual building through real-time online. BIM technology is a dual information digital technology. Civil engineering applications can achieve comprehensive project management and enhance the economic and social benefits of civil engineering ${ }^{[1]}$.

\subsection{Characteristics of BIM technology}

\subsubsection{Visualization}

The visualization of BIM technology mainly realizes the conversion of the traditional two-dimensional engineering architecture design into three-dimensional design, and the visualization of civil engineering design and architecture. Currently, the visualization of the model can provide more technical support for the construction site. Through the lightweight of the model to reduce the model's dependence on computer hardware, the lightweight model can be easily passed into the relevant cloud platform or mobile terminal, construction and management personnel through the cloud platform or mobile terminal can browse the engineering model at the construction site, review the details of the relevant construction nodes, check the construction quality, support the field office.

\subsubsection{Simulation}

BIM technology has excellent simulation characteristics mainly in the implementation of civil engineering projects, which can simulate the relevant design models and control engineering risks within a relatively reasonable 
range. In the MEP design phase, through the MEP between the various specialties, MEP and civil engineering model, decorative model of the collision check and pipeline design, under the premise of meeting the construction process and building height requirements, the pipeline for the comprehensive design and output of the relevant MEP construction drawings to guide the construction of electromechanical pipelines and hangers.

\subsubsection{Adjustability}

The application of BIM technology to civil engineering can achieve good coordination among various departments and processes. In the model, the sharing of building information is realized, so that the relevant designers and builders can implement collaborative design and management integration directly from the model, thus avoiding various engineering problems caused by poor communication between the existing design and construction models, and thus reducing the loss of management costs caused by poor communication, and ultimately achieving improved management efficiency.

\section{BIM technology application process in civil engineering}

\subsection{Data collection}

In order to ensure the effectiveness of BIM technology in civil engineering, relevant engineers must create $3 \mathrm{D}$ building models based on the project specifics. When building the model, engineering data information is crucial. The relevant engineering designer should thoroughly investigate the actual conditions on the project site and obtain the most comprehensive engineering information. The engineering information must be complete and true. On the basis of this engineering information, after synthesizing various information, engineering information is stored in electronic and digital formats to build engineering information platform. At the construction site, the field engineer can establish the barcode of this constructed information (e.g., location, materials, construction information, etc.) in the relevant components, which should correspond to the components in the model.

2.2 Establish system structure

Establish civil engineering system structure based on data and engineering structure. The main purpose of the system structure is to achieve the following objectives: to achieve the supervision and management of project construction activities, to strengthen the coordination and cooperation between construction units, to achieve $3 \mathrm{D}$ simulation, and to query the relevant engineering data information. Therefore, the construction of the civil engineering system structure should be carried out according to the actual project construction in order to ensure good dynamic management during the execution of the project.

\subsection{Refine the construction process}

The scientific nature of the BIM model requires not only the effective integration of construction data and information, but also the detailed analysis of various data generated during the construction process as well as the detection of various problems in construction. The application of BIM technology effectively achieves the improvement of the construction process, the integrated management of the construction process and the rational use of engineering resources ${ }^{[2]}$. BIM + mobile applications, which can use mobile to the field construction personnel Conducting technical handover, management personnel can send the field problems to the project management platform through mobile terminal, so as to facilitate the construction party to rectify the problems. With the application of BIM+VR, a point cloud model is established through 3D scanning, and a $3 \mathrm{D}$ digital model is built for the building according to the point cloud model, which provides a basis for the construction repair in the operation and maintenance stage.

\section{Application of BIM technology in civil engineering}

\subsection{Design phase}

BIM technology plays an important role in the design phase of civil engineering. In the engineering design phase, the focus of the relevant designers is to model a complete data information structure based on information and data sharing to visualize the specifics of the project and to clearly represent the local contours of the project composition. For example, the engineering designer may enter relevant geographic and geological information and other parameters into the model so that the model accurately and objectively reflects the actual appearance of the project ${ }^{[3]}$. The engineering information contained in the design phase is very complex, so designers need to fully understand the integration of data before using it effectively, and BIM models can be used effectively to achieve the integration of data, which is particularly important for civil engineering design plans. Out of science and rationality, BIM models are more systematically coordinated, and good communication between designers can be carried out to effectively solve various problems in the design plan, realize the effective use of engineering resources, and improve the 
overall design level. Therefore, BIM technology plays an important role in the design phase, and its application process is shown in Figure $1^{[4]}$.

\section{engineering construction management}

The quality of civil construction management not only affects the schedule of the project, but also determines

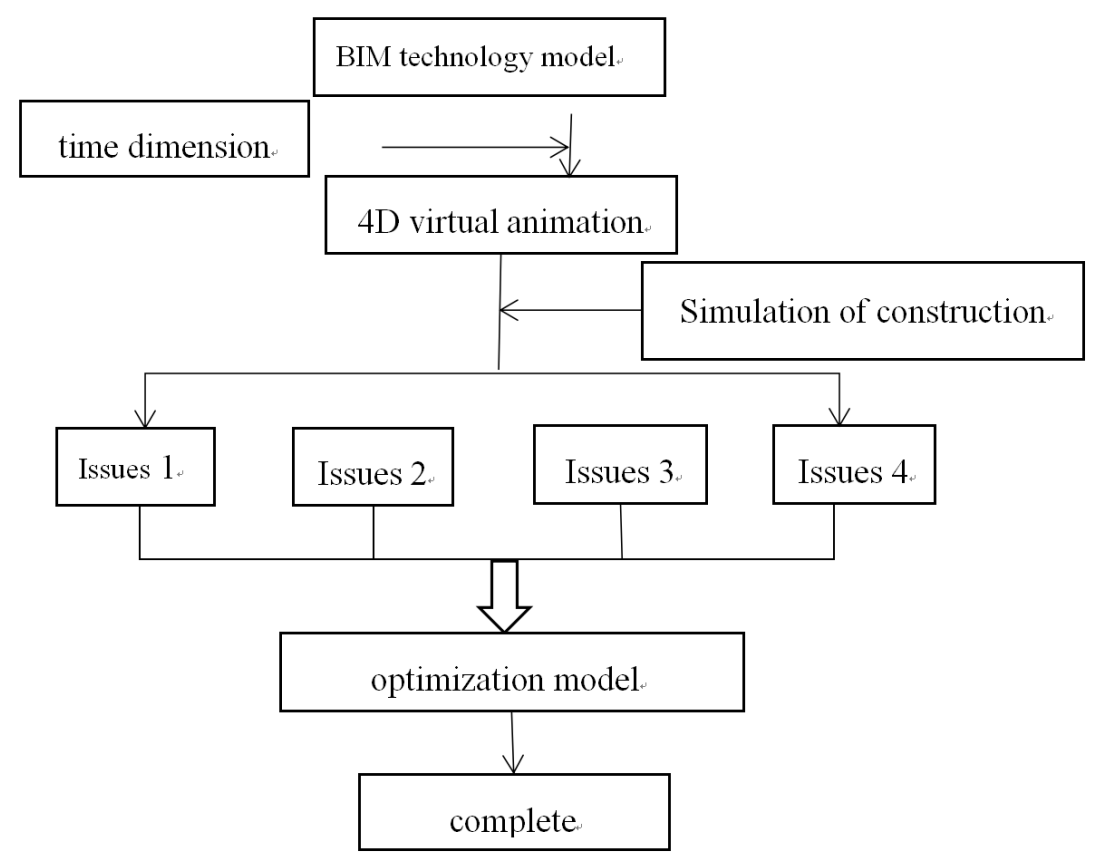

Figure 1. BIM technology in the engineering design phase process diagram

\subsection{Structural simulation}

In the construction of civil engineering projects, the application of BIM technology establishes a complete three-dimensional simulation space of civil engineering, which is an important part of the advantages of BIM technology. In fact, the creation of project-related data and parameters requires detailed processing of the $3 \mathrm{D}$ space based on project information data, and a relatively complete data model can be created after data integration and other processing ${ }^{[5]}$. Typically, the model consists of two key models and an engineering model from the perspective of the data integration and modeling process. The key engineering model enables relevant engineering managers to execute civil engineering projects in order to understand the real-time execution of the project's construction objectives, and the engineering model clearly shows the specific processes and details of each construction step. Therefore, when applying BIM technology to civil engineering, it is important to ensure that the model information is complete and accurate. Otherwise, it will affect the overall effectiveness of the modeling. By enhancing the processing related to all aspects of engineering information during the modeling process, it should be possible to achieve excellent dynamic and comprehensive management of the construction process in the future.

\subsection{BIM technology for optimization of civil}

the quality and cost of the project. Traditional civil construction management focuses on basic issues, such as building materials management and personnel reserve in the construction process. In accounting, it is difficult to effectively control the use of funds in different departments, while the application of BIM technology allows information resources to be shared on the same system, which provides great convenience for construction management. First of all, the improvement and optimization of the design process provides a wide operating space for the smooth development of future construction management. Identifying particularly important and difficult sections through engineering simulation can inform the construction manager in specific supervision and management, and can accurately identify the construction of a project. Important and difficult matters are effective in improving the efficiency of construction management. Secondly, the application of BIM technology can help the cost engineer to use computer software technology for the input and calculation of design drawing information, while the simulation configuration allows for highspeed and accurate calculation of quantities, so it is important to determine the estimated cost of the project ${ }^{[5]}$. Finally, the application of BIM technology to construction management allows for coordination and collaboration between multiple departments. For example, during the construction process, it is possible to gain direct in- 
sight into design plans or to find solutions through models. Problems found during construction supervision can also be conveyed through the BIM technology platform, and even the design department can be asked to provide an accurate description to ensure construction quality.

\section{Conclusion}

With the development of time and science and technology, BIM technology has become an emerging technology with digital flow modeling as the core technology, and has been applied to civil engineering. We can not only improve the construction efficiency of civil engineering effectively in the construction process, but also avoid the problems that may occur in the construction process and take targeted measures against the problems that occur in the project in order to effectively ensure the construction efficiency of civil engineering. At present, BIM technology is in the development stage in China, and it can play a great role as a new technology.
This paper provides a theoretical basis for the application of BIM technology in the background of the era of big data, and provides scientific and effective help for the future civil engineering construction.

\section{References}

[1] Wang N, Wang XG, Zhang YM, et al. Discussion on the application of BIM technology in the training of civil engineering professionals[J]. Journal of North China University of Technology (Social Science Edition), 2019, 19(4): 94+98+95-97.

[2] Wang B. Research on the 3D design method of road based on BIM technology[D]. Lanzhou Jiaotong University, 2018.

[3] Zhu QG. Application of BIM technology in civil engineering construction in the context of smart manufacturing[J]. Building Materials and Decoration, 2018(50): 16-17.

[4] Wang W, Li HJ, Liu Y. Application and Practice of BIM Technology in Joint School-Enterprise Graduation Design[J]. Higher Architecture Education, 2018, 27(6): 161-166.

[5] Fan DL. Application innovation of civil engineering construction technology in the context of intelligent[J]. Smart Buildings and Smart Cities, 2020(7): 93-95. 